\title{
Cerebral microdialysis: research technique or clinical tool
}

\author{
Martin M Tisdall and Martin Smith \\ Department of Neuroanaesthesia and Neurocritical Care, The National Hospital for \\ Neurology and Neurosurgery, Queen Square, London WC1N 3BG \\ Centre for Anaesthesia, University College London
}

\section{Corresponding Author:}

Dr Martin Smith

Department of Neuroanaesthesia and Neurocritical Care

Box 30

The National Hospital for Neurology and Neurosurgery

Queen Square

London

WC1N 3BG

Email: martin.smith@uclh.org

Tel: $\quad 02078298711$

Fax: 02078298734

Running Title: Cerebral microdialysis: a clinical review 


\section{Summary}

Cerebral microdialysis is a well-established laboratory tool that is increasingly used as a bedside monitor to provide on-line analysis of brain tissue biochemistry during neurointensive care. This review describes the principles of cerebral microdialysis and the rationale for its use in the clinical setting, including discussion of the most commonly used microdialysis biomarkers of acute brain injury. Potential clinical applications are reviewed and future research applications identified. Microdialysis has the potential to become an established part of mainstream multimodality monitoring during the management of acute brain injury but at present should be considered a research tool for use in specialist centres.

Keywords Brain - injury, Monitoring - intensive care, Metabolism - metabolites, Monitoring - microdialysis 


\section{Introduction}

In 1966 Bito inserted membrane lined sacks containing 6\% dextran into the cerebral hemispheres of dogs. ${ }^{7}$ The sacks were removed 10 weeks later and the fluid they contained was analysed for levels of amino acids. During the 1970s this technique was refined and developed into cerebral microdialysis (MD), in which a perfusate solution is passed along a semi-permeable membrane inserted in the brain parenchyma, allowing continuous sampling of the brain extracellular fluid. ${ }^{10,51,52}$ The use of cerebral MD gained in popularity in the early 1990's when commercially produced microdialysis catheters and a bedside diasylate analyser (CMA Microdialysis, Solna, Sweden) became available.

Cerebral MD is a well established laboratory tool and is being increasingly used as a bedside monitor to provide on-line analysis of brain tissue biochemistry during neurointensive care. This review will briefly describe the principles and rationale behind MD and discuss its use in the context of the management of acute brain injury (ABI).

\section{Principles of Microdialysis}

The principles of MD have been reviewed in detail elsewhere ${ }^{5,14,22,25}$ but a brief summary is provided here. A MD catheter consists of a fine double lumen probe, lined at its tip with a semi-permeable dialysis membrane. The probe tip is placed into biological tissue and perfused via an inlet tube with fluid isotonic to the tissue interstitium. The perfusate passes along the membrane before exiting via outlet tubing into a collecting chamber (figures 1 and 2). Diffusion drives the passage of molecules across the membrane along their concentration gradient. Molecules at high concentration in the brain extracellular fluid (ECF) pass into the perfusate with minimum passage of water and, as the perfusate flows and is removed at a constant rate, the concentration gradient is maintained. The MD catheter therefore acts an artificial blood capillary and the concentration of substrate in the collected fluid (microdialysate) will depend in part on the balance between substrate delivery to, and uptake/excretion from, the ECF (Figure 3). This simple concept provides a powerful 
technique with many potential applications in which any molecule small enough to pass across the membrane can be sampled.

It is instantly apparent that the concentration of a given molecule in the diasylate will be lower than its concentration in the brain ECF unless there is total equilibration across the dialysis membrane. The proportion of the true ECF concentration collected in the diasylate is termed the relative recovery and is dependent on membrane pore size, membrane area, rate of flow of perfusate and diffusion speed of the substance.

When comparing measured MD values it is essential to consider the sampling methods and materials used. In clinical practice the most commonly used system comprises a catheter that is $10 \mathrm{~mm}$ in length with a $20 \mathrm{kDa}$ (CMA 70, CMA/Microdialysis) or $100 \mathrm{kDa}$ (CMA 71, CMA/Microdialysis) molecular weight cut-off, perfused with commercially available perfusate solution (Perfusion Fluid CNS, CMA/Microdialysis) at a rate of $0.3 \mu \mathrm{L} \mathrm{min}{ }^{-1}$. The advantage of a $100 \mathrm{kDa}$ molecular weight cut-off catheter is the ability to investigate higher molecular weight biomarkers, but such catheters have equivalent recovery to $20 \mathrm{kDa}$ cut-off catheters for the more conventional, and clinically relevant, MD variables such as glucose, lactate, pyruvate, glutamate and lactate:pyruvate ratio. ${ }^{19}$ All microdialysate concentrations quoted in this review refer to the above system and a flow rate of $0.3 \mu \mathrm{L} \mathrm{min}{ }^{-1}$.

\section{Why monitor tissue biochemistry in the injured brain?}

Acute brain injury $(A B I)$ is frequently exacerbated by secondary events that lead to secondary brain injury, which is a potentially modifiable cause of mortality and morbidity after $A B I$. Secondary injury to the brain occurs following activation by the primary injury of an auto-destructive cascade of metabolic, immunological and biochemical changes that render the brain more susceptible to secondary physiological insults and ultimately result in irreversible cell damage or death. ${ }^{50}$ These poorly understood pathological processes lead to failing cellular metabolism, calcium overload, increased production of free radicals and 
release of neurotoxic levels of excitatory amino acids. If unchecked, these changes cause cellular swelling, rises in intracranial pressure and further neuronal loss resulting in increased mortality and worsened outcome in survivors. Treatment of $\mathrm{ABI}$ during neurointensive care is aimed at preventing or minimising the burden of secondary injury. Monitoring brain tissue biochemistry has the potential to identify impending or early-onset secondary injury and allow timely implementation of neuroprotective strategies. Many neurocritical care units have adopted protocolised, stepwise interventions for the treatment of $\mathrm{ABI}^{48}$ and cerebral MD may allow assessment of the adequacy of treatment in an individual patient at a particular moment in time and therefore has the potential to guide individualised and targeted therapy after $\mathrm{ABI}$.

\section{Catheter Placement}

MD monitors local tissue biochemistry and reflects metabolic disturbances and neurochemical changes only in the part of the brain where the probe is located. Wide differences between MD measured variables have been reported in areas close to, and far away from, focal traumatic lesions. ${ }^{12}$ Placement of the MD catheter in 'at risk' tissue, such as the area surrounding a mass lesion after traumatic brain injury (TBI), or the vascular territory most likely to be affected by vasospasm after subarachnoid haemorrhage (SAH), allows biochemical changes to be measured in the area of brain most vulnerable to secondary damage (figure 4). In the case of diffuse axonal injury catheter placement in the nondominant frontal lobe is recommended. Guidance has been issued on catheter placement for monitoring patients after TBI and $\mathrm{SAH} .{ }^{2}$ Commercial MD catheters incorporate a gold tip and, because the site of placement is crucial, the tip position should be checked by subsequent computed tomography scan.

\section{Microdialysis markers}

The most common, commercially available, assays for bedside use are those for glucose, lactate, pyruvate, glycerol and glutamate, and tentative normal values for these variables 
have been described (Table 1). Reinstrup et al., inserted MD catheters into the posterior frontal cortex of patients undergoing surgery for benign posterior fossa lesions and collected microdialysate samples in the post-operative course in order to demonstrate baseline metabolite concentrations from the uninjured human brain. ${ }^{37}$ In another study, concentrations of metabolites in microdialysate samples from SAH patients with no clinical or radiological evidence of cerebral ischaemia were considered to represent normal values. ${ }^{49}$ A summary of the pathophysiological changes monitored by cerebral MD biomarkers is shown in table 2.

\section{Markers of glucose metabolism}

One of the main advantages of cerebral MD monitoring after $A B I$ is the ability to assess the cerebral delivery and utilisation of glucose. This is the main source of energy to the brain and a continued supply of glucose is vital for the maintenance of the integrity of the cell. Microdialysate glucose levels are reduced in patients following traumatic brain injury (TBI), and a concentration consistently less than $0.66 \mathrm{mmol} \mathrm{I}^{-1}$ in the first 50 hours post TBI is associated with poor outcome. ${ }^{57}$ The aetiology of this low glucose concentration is likely to be multifactorial. In the acute period after TBI there is typically a reduction in oxidative metabolism ${ }^{16}$ and increase in glucose metabolism. ${ }^{6}$ Extremely low levels of cerebral MD glucose are observed during periods of severe hypoxia/ischaemia after $\mathrm{TBI}^{13,24}$ and subarachnoid haemorrhage $(\mathrm{SAH}),{ }^{53}$ and are associated with a brain tissue $\mathrm{pO}_{2}\left(\mathrm{PbrO}_{2}\right)$ of less than $1.3 \mathrm{kPa} .{ }^{38,54}$ However, a poor correlation has been shown between ischaemia defined by positron emission tomography (PET) imaging and low MD glucose concentration ${ }^{58}$ suggesting that, in some cases at least, low MD glucose concentration may be associated with hyperglycolysis rather than critical supply of glucose and oxygen because of reduced cerebral perfusion.

Glycolysis involves the metabolism of glucose to pyruvate and is perturbed after ABI. ATP production proceeds via the aerobic pathway through electron complex mediated reduction 
of oxygen, or via the inefficient anaerobic pathway resulting in the formation of lactate. The measurement of MD lactate and pyruvate concentrations provides information on the extent of anaerobic glycolysis, and the extracellular lactate:pyruvate ratio (LPR) reflects the intracellular redox state - a marker of mitochondrial function. ${ }^{34,45}$. LPR is a more robust and reliable biomarker of tissue ischaemia than lactate concentration alone ${ }^{11}$ and, because lactate and pyruvate have very similar molecular weights, the LPR is independent of catheter recovery in vivo. ${ }^{33}$ LPR is therefore the most widely monitored MD variable after $A B I$.

In the human brain, severe hypoxia/ischaemia is typically associated with marked increases in the $\mathrm{LPR}^{49}$ which correlates with PET measured oxygen extraction fraction. ${ }^{18}$ An increase in LPR above established thresholds (20-25) is associated with poor outcome in $\mathrm{TBI}^{17,59}$ and $\mathrm{SAH}^{23,35,41}$, and has traditionally been assumed to indicate tissue ischaemia. However, it has proved difficult to establish the tissue hypoxic threshold for a raised $\mathrm{LPR}^{21}$ and it is increasingly apparent that anaerobic glycolysis may occur due to failure of effective utilization of delivered oxygen because of mitochondrial failure as well as because of hypoxia/ischaemia. ${ }^{58}$

The lactate:glucose ratio is also a sensitive marker of tissue hypoxia/ischaemia and has been interpreted as indicating increased glycolysis. ${ }^{43}$

\section{Glutamate}

Excitotoxicity is a proposed mechanism of secondary brain injury, mediated by excessive calcium influx into brain cells via glutamate mediated ion channels. Early excitement surrounding the measurement of MD glutamate concentration was fuelled by animal studies demonstrating raised MD glutamate concentration in global cerebral ischaemia ${ }^{4}$ and TBI. ${ }^{29}$ Cerebral ischaemia in humans is associated with an increased MD glutamate concentration ${ }^{18}$ and the degree of MD glutamate rise correlates with poor outcome after $\mathrm{TBI}^{17}$ and $\mathrm{SAH} .{ }^{23,35}$ However the key role of glutamate in excitotoxicity after TBI has been 
challenged $^{31}$ and the initial enthusiasm for the clinical measurement of MD glutamate concentration after $\mathrm{ABI}$ has waned.

\section{Glycerol}

Failure of cellular metabolism results in disruption of cell membrane function and ultimately leads to degradation of cell membrane phospholipids and release of glycerol, an end product of phospholipid breakdown, into the brain ECF. Glycerol is therefore a useful MD marker of tissue hypoxia and cell damage after $\mathrm{ABI}^{9}$ and the degree of the hypoxia/ischaemia induced elevation of MD glycerol may be dramatic, with four- or eight-fold increases recorded in severe or complete ischaemia respectively. ${ }^{43}$ Cerebral MD glycerol concentrations are typically elevated in the first 24 hours after severe TBI, presumably as a result of the primary injury, and then exponentially decline during the ensuing 3 days. ${ }^{9}$ Subsequent increases in MD glycerol concentration are associated with adverse secondary events ${ }^{37}$ and seizure activity. ${ }^{55}$

\section{Clinical applications of MD monitoring}

Before considering the use of cerebral MD as a clinical monitor after $\mathrm{ABI}$, it is important to understand that there are wide variations in MD variables over time after the injury, not only between different subjects, but also within individuals. ${ }^{17,34,35,47}$ These are likely to represent the high and changing levels of metabolic activity within the injured brain ${ }^{18}$ but make it difficult to interpret 'one off' MD measurements in isolation. Despite the publication of 'normal' values, cerebral MD must therefore be seen as a trend monitor, with the data being interpreted in association with other measure variables.

There is a large body of literature suggesting that MD monitoring is able to predict poor outcome after TBI and $\mathrm{SAH}$, and some of this has been discussed earlier in this review. There is also some evidence that MD may assist clinical decision making, such as management of cerebral perfusion pressure, ${ }^{30}$ guidance of hyperventilation ${ }^{26}$ and the 
appropriateness of extensive surgical procedures. ${ }^{8}$ However to offer added value over and above that provided by other intracranial monitors, cerebral MD must not only guide treatment, but do so in a way that reduces the burden of secondary brain injury and thereby offer the potential to improve functional outcome in survivors.

The value of the placement of the MD catheter in 'at risk' tissue has been demonstrated in a recent study of 33 patients with severe TBI. ${ }^{15}$ Focal measurements using $\mathrm{MD}$ and $\mathrm{PbrO}_{2}$ were made in brain tissue underlying an evacuated subdural haematoma and were compared to global measures of intracranial pressure (ICP), cerebral perfusion pressure (CPP) and jugular venous oxygen saturation $\left(\mathrm{SjvO}_{2}\right) .17$ of the 33 patients developed delayed focal secondary injury (contusion or infarction) and showed reduced $\mathrm{PbrO}_{2}$ and elevation of MD LPR in the absence of global changes in ICP, CPP or $\mathrm{SjvO}_{2}$. However, in the 11 patients with an uneventful clinical course, there were no changes in $\mathrm{MD}$ and $\mathrm{PbrO}_{2}$. The remaining 5 patients suffered fatal refractory intracranial hypertension and demonstrated a classic pattern of change in MD biomarkers, i.e. markedly elevated LPR and glutamate, and reduced glucose. These data confirm that focal monitoring of biochemical changes in 'at risk' brain tissue using MD may, in association with $\mathrm{PbrO}_{2}$ monitoring, provide clinically useful indications of evolving brain injury at the bedside.

Elevated LPR is a sensitive marker of ischaemia after $A B I$ and, although its interpretation may be complicated by mitochondrial failure, it is intuitively an attractive monitor of the adequacy of cerebral oxygen delivery. Nordstrom et al. studied 50 patients with severe TBI using a MD catheter placed in the 'at risk' tissue surrounding a focal lesion and a second in the contralateral frontal lobe ('normal' tissue). ${ }^{30}$ The lactate concentration was higher in the 'at risk' compared to 'normal' brain and LPR increased in the 'at risk' tissue when CPP fell below $50 \mathrm{mmHg}$ (see also figure 4). It was concluded that cerebral MD can be used to assess the safe lower limit of CPP, suggesting that CPP management might be individualised rather than delivered to a generic target value. 
Patients suffering from SAH have a significant incidence of cerebral vasospasm, which may lead to cerebral ischaemia. MD glutamate and glycerol concentrations correlate with regional cerebral blood flow assessed using PET after SAH, and LPR ratio shows high sensitivity and specificity for symptoms of ischaemia. ${ }^{42} \mathrm{MD}$ therefore has the potential not only to assist in the diagnosis of significant vasospasm, but also to guide triple $\mathrm{H}$ therapy. This may be particularly useful in the unconscious patient in whom clinical examination is not possible.

As cerebral MD measures changes at the cellular level, it also has the potential to detect hypoxia/ischaemia before changes can be detected in the patient's neurological status or by more conventional monitoring techniques such as ICP measurement. In patients with severe $\mathrm{TBI}$, rise in LPR and glycerol predicted intracranial hypertension in the following three hours ${ }^{47}$ and, after SAH, these same biomarkers predicted the occurrence of a delayed ischaemic deficit related to cerebral vasospasm 11-23 hours before its clinical appearance. ${ }^{46}$ However, despite data highlighting the predictive value of MD, one study found no correlation between MD glycerol concentration and secondary events, such as intracranial hypertension and low CPP, in 15 patients with TBI. ${ }^{32}$ Glutamate should be an attractive biomarker for the prediction of secondary injury and, although a recent study failed to demonstrate a predictive value of increased glutamate concentration after $\mathrm{TBI},{ }^{47}$ it does appear to be a sensitive indicator of impending cerebral ischaemia after $\mathrm{SAH}{ }^{28}$

In a recent study, Clausen et al. examined the relationship between $\mathrm{PbtO}_{2}, \mathrm{MD}$ glycerol, CPP and outcome in 76 patients with severe TBI. ${ }^{9}$ Although $\mathrm{PbtO}_{2}<1.3 \mathrm{kPa}$ and $\mathrm{CPP}<70$ $\mathrm{mmHg}$ were associated with elevated mean cerebral MD glycerol levels, individual episodes below the same thresholds were frequently recorded without an increase in MD glycerol concentration. There was also no difference in mean MD glycerol concentrations between patients with favourable and unfavourable outcomes. In another study, the effects of norepineprine-induced augmentation of CPP (from 70 to $90 \mathrm{mmHg}$ ) were examined in 11 
patients with severe TBI. There were significant increases in $\mathrm{PbtO}_{2}$ that were associated with increases in cerebral blood flow and decreases in oxygen extraction ratio measured by PET following the increase in CPP, but there were no significant changes in MD glucose, lactate, pyruvate or glycerol. ${ }^{21}$ These, and other studies, suggest that further investigation is required to determine the validity of cerebral MD variables in different clinical settings.

One of the important contributions of cerebral MD during neurointensive care is its ability to increase our understanding of the effect that current treatment strategies have on the injured brain. For example, MD glucose concentration can be manipulated by altering systemic glucose concentration in both the normal ${ }^{1}$ and injured ${ }^{56}$ brain. Poor outcome in the acute phase after severe TBI is associated with high systemic glucose concentrations ${ }^{20}$ but also with but low cerebral MD glucose concentrations. ${ }^{57}$ In a recent study, tight systemic glycaemic control (defined in this study as serum glucose concentration of $5.0-6.7 \mathrm{mmol} \mathrm{I}^{-1}$ ) did not improve functional outcome after TBI and was associated with increased incidence of MD markers of cellular distress. ${ }^{56}$ This finding merits further investigation and suggests that established targets for glycaemic control after TBI might not be universally applicable and that measurement of cerebral MD glucose concentration has the potential to guide individualised systemic glucose management.

\section{Research Applications of MD}

Any molecule present in the cerebral ECF that is small enough to cross the semi-permeable dialysis membrane will be collected in the diasylate. This opens the door to the investigation of novel biomarkers of $\mathrm{ABI}$ and several promising avenues of research are being pursued. Recent work has included measurement of nitric oxide metabolites, ${ }^{40} \mathrm{~N}$-acetylaspartate ${ }^{3}$ and $\mathrm{S} 100 \mathrm{~B}^{44}$, but the possible applications are myriad and as yet unexplored. A potentially exciting new field is the application of proteomics to MD and this approach has already been applied in an explorative study of three patients with thromboembolic stroke. ${ }^{27}$ Cerebral MD can also be used to investigate drug penetration in the human brain and as a tool during 
drug trials. Finally, it is possible to engineer the delivery of substances to the brain using MD and this has potential applications in the field of brain tumour chemotherapy. ${ }^{36,39}$

\section{Conclusion}

Cerebral MD allows measurement of local tissue biochemistry, and the introduction of a commercially available analyser has made on-line cerebral MD monitoring a reality. MD is the only method of measuring brain tissue biochemistry at the bedside and it is a useful tool for the detection of biochemical changes associated with hypoxia/ischaemia after $A B I$. There is some evidence that MD also has the potential to provide early warning of impending hypoxia/ischaemia and neurological deterioration, and this may allow timely implementation of neuroprotective strategies. However, MD reflects only local tissue biochemistry and accurate placement of the catheter is crucial. Furthermore, because there are wide variations in measured variables, trend data are more important than absolute values.

Although MD is used routinely in a few centres it has not yet been introduced into widespread clinical practise and, at present, should be considered a research tool for use in specialist centres. Although clinical experience is rapidly increasing, carefully designed prospective studies are required to determine the value of cerebral MD in the management of patients with $\mathrm{ABI}$. However, because of its unique ability to contribute important information about the process of secondary brain injury, MD has the potential to become established as a key component of multi-modality monitoring during management of $A B I$ during neurointensive care.

Acknowledgements: MT is a Welcome Research Fellow, Grant No 075608 The authors are grateful to CMA Microdialysis (Solna, Sweden) for permission to reproduce and modify the figures. 


\section{Reference}

1. Abi-Saab W.M., Maggs DG, Jones T. et al. Striking differences in glucose and lactate levels between brain extracellular fluid and plasma in conscious human subjects: effects of hyperglycaemia and hypoglycaemia. J Cereb Blood Flow Metab 2002;22:271-9

2. Bellander BM, Cantais E, Enblad P et al. Consensus meeting on microdialysis in neurointensive care. Intensive Care Med 2004;30:2166-9

3. Belli A, Sen J, Petzold A et al. Extracellular N-acetylaspartate depletion in traumatic brain injury. Journal of Neurochemistry 2006;96:861-9

4. Benveniste H, Drejer J, Schousboe A, Diemer NH. Elevation of the extracellular concentrations of glutamate and aspartate in rat hippocampus during transient cerebral ischaemia monitored by intracellular microdialysis. J Neurochem 1984;43:1369-74

5. Benveniste H, Huttemeir PC. Microdialysis - Theory and Application. Prog Neurobiol 1990;35:195-215

6. Bergsneider MA, Hovda DA, Shalmon E et al. Cerebral hyperglycolysis following severe human traumatic brain injury: a positron emission tomography study. $J$ Neurosurg 1997;86:241-51

7. Bito L, Davson H, Levin EM, Murray M, Snider N. The concentration of free amino acids and other electrolytes in cerebrospinal fluid in vivo diasylate of brain blood plasma of the dog. J Neurochem 1966;13:1057-67

8. Boret H, Fesselet J, Meaudre E, Gaillard PE, Cantais E. Cerebral microdialysis and Ptio2 for neuro-monitoring before decompressive craniectomy. Acta Anaesthesiologica Scandinavica 2006;50:252-4 
9. Clausen T, Alves OL, Reinert M, Doppenberg E, Zauner A, Bullock R. Association between elevated tissue glycerol levels and poor outcome following severe traumatic brain injury. J Neurosurg 2005;103:233-8

10. Delgado JM, DeFeudis FV, Roth RH, Ryugo DK, Mitruka BM. Dialytrode for long term intracerebral perfusion in awake monkeys. Arch Int Pharmacodyn Ther 1972;198:9-21

11. Enblad $\mathrm{P}$, Valtysson $\mathrm{J}$, Andersson $\mathrm{J}$ et al. Simultaneous intracerebral microdialysis and positron emission tomography in the detection of ischemia in patients with subarachnoid hemorrhage. J Cereb Blood Flow Metab 1996;16:637-44

12. Engstrom M, Polito A, Reinstrup $P$ et al. Intracerebral microdialysis in severe brain trauma: the importance of catheter location. J Neurosurg 2005;102:460-9

13. Goodman JC, Valadka AB, Gopinath SP, Uzura M, Robertson CS. Extracellular lactate and glucose alterations in the brain after head injury measured by microdialysis. Crit Care Med 1999;27:1965-73

14. Hillered L, Vespa PM, Hovda DA. Translational neurochemical research in acute human brain injury: the current status and potential future for cerebral microdialysis. $J$ Neurotrauma 2005;22:3-41

15. Hlatky R, Valadka A, Goodman J, Robertson C. Evolution of brain tissue injury after evacuation of acute traumatic subdural haematoma. Neurosurgery 2004;55:1318-23

16. Hovda DA, Yoshino A, Kawamata T, Katayama Y, Becker D. Diffuse prolonged depression of cerebral oxidative metabolism following concussive brain injury in the rat: a cytochrome oxidase histochemistry study. Brain Res 1991;3:1-10

17. Hutchinson PJ, Al-Rawi PG, O'Connell MT et al. On-line monitoring of substrate delivery and brain metabolism in head injury. Acta Neurochir Supp/ 2000;76:431-5 
18. Hutchinson PJ, Gupta AK, Frywe T.F. et al. Correlation between cerebral blood flow, substrate delivery, and metabolism in head injury: a combined microdialysis and triple oxygen positron emission tomography study. J Cereb Blood Flow Metab 2002;22:73545

19. Hutchinson PJ, O'Connell MT, Nortje $\mathrm{J}$ et al. Cerebral microdialysis methodology evaluation of 20 kDa and 100 kDa catheters. Physiological Measurement 2005;423-8

20. Jeremitsky E, Omert LA, Dunham CM, Wilberger J, Rodriguez A. The impact of hyperglycemia on patients with severe brain injury. J Neurotrauma 2005;58:47-50

21. Johnston AJ, Steiner LA, Coles JP et al. Effect of cerebral perfusion pressure augmentation on regional oxygenation and metabolism after head injury. Crit Care Med 2005;33:189-95

22. Kehr J. A survey on quantitative microdialysis: theoretical models and practical implications. J Neurosci Methods 1993;48:251-61

23. Kett-White R, Hutchinson PJ, AI-Rawi PG, Gupta AK, Pickard JD, Kirkpatrick PJ. Adverse cerebral events detected after subarachnoid hemorrhage using brain oxygen and microdialysis probes. Neurosurgery 2002;50:1213-21

24. Langemann $\mathrm{H}$, Mendelowitsch $\mathrm{A}$, Landolt $\mathrm{H}$, Alessandri $\mathrm{B}$, Gratzl O. Experimental and clinical monitoring of glucose by microdialysis. Clin Neurol Neurosurg 1995;97:149-55

25. Lindefors N, Amberg G, Ungerstedt U. Intracerebral microdialysis : 1 Experimental studies of diffusion kinetics. J Pharmacol Methods 1989;22:141-56

26. Marion DW, Puccio A, Wisniewski SR et al. Effect of hyperventilation on extracellular concentrations of glutamate, lactate, pyruvate, and local cerebral blood flow in patients with severe traumatic brain injury. Crit Care Med 2002;30:2619-25 
27. Maurer $\mathrm{MH}$, Berger $\mathrm{C}$, Wolf $\mathrm{M}$ et al. The proteome of human brain microdialysate. Proteome Sci 2003;1:7

28. Nilsson OG, Brandt L, Ungerstedt U, Saveland H. Bedside detection of brain ischemia using intracerebral microdialysis: subarachnoid hemorrhage and delayed ischemic deterioration. Neurosurgery 1999;45:1176-84

29. Nilsson P, Hillered L, Ponten U, Ungerstedt U. Changes in cortical extracellular levels of energy-related metabolites and amino acids following concussive brain injury in rats. J Cereb Blood Flow Metab 1990;10:631-7

30. Nordstrom C, Reinstrup P, Xu W, Gardenfors A, Ungerstedt U. Assessment of lower limit for cerebral perfusion pressure in severe head injuries by bedside monitoring of regional energy metabolism. Anesthesiology 2003;98:809-14

31. Obrenovitch TP, Urenjak J. Is high extracellular glutamate the key to excitotoxicity in traumatic brain injury? J Neurotrauma 1997;14:677-98

32. Peerdeman SM, Girbes AR, Polderman KH, Vandertop W. Changes in interstitial glycerol concentration in head-injured patients: correlation with clinical events. Intensive Care Med 2003;29:1825-8

33. Persson L, Hillered L. Intracerebral microdialysis. J Neurosurg 1996;85:984-5

34. Persson L, Hillered L. Chemical monitoring of neurosurgical intensive care patients using intracerebral microdialysis. J Neurosurg 1992;76:72-80

35. Persson L, Valtysson J, Enblad P et al. Neurochemical monitoring using intracerebral microdialysis in patients with subarachnoid hemorrhage. J Neurosurg 1996;84:606-16

36. Redgate ES, Boggs S, Grudziak A, Deutsch M. Polyamines in brain tumour therapy. J Neurooncol 1995;25:167-79 
37. Reinstrup P, Stahl N, Mellergard P, Uski T, Ungerstedt U, Nordstrom CH. Intracerebral microdialysis in clinical practice: baseline values for chemical markers during wakefulness, anesthesia, and neurosurgery. Neurosurgery 2000;47:701-9

38. Robertson CS, Gopinath SP, Uzura M, Valadka AB, Goodman JC. Metabolic changes in the brain during transient ischemia measured with microdialysis. Neurol Res 1998;20 Suppl 1:91-4

39. Ronquist G, Hugosson R, Sjolander U, Ungerstedt U. Treatment of malignant glioma by a new therapeutic principle. Acta Neurochir (Wien) 1992;114:8-11

40. Sakowitz OW, Wolfrum S, Sarrafzadeh AS, Stover JF, Lanksch WR, Unterberg AW. Temporal profiles of extracellular nitric oxide metabolites following aneurysmal subarachnoid hemorrhage. Acta Neurochir (Wien) 2002;S81:351-4

41. Sarrafzadeh A, Haux D, Kuchler I, Lanksch WR, Unterberg AW. Poor-grade aneurysmal subarachnoid hemorrhage: relationship of cerebral metabolism to outcome. J Neurosurg 2004;100:400-6

42. Sarrafzadeh AS, Haux D, Ludemann L et al. Cerebral ischemia in aneurysmal subarachnoid hemorrhage: a correlative microdialysis-PET study. Stroke 2004;35:63843

43. Schulz M, Wang L, Tange M, Bjerre $\mathrm{P}$. Cerebral microdialysis monitoring: determination of normal and ischemic cerebral metabolism in patients with aneurysmal subarachnoid hemorrhage. J Neurosurg 2000;93:233-8

44. Sen J, Belli A, Petzold A et al. Extracellular fluid S100B in the injured brain: a future surrogate marker of acute brain injury? Acta Neurochir (Wien) 2005;147:897-900

45. Siesjo BK. Cerebral circulation and metabolism. J Neurosurg 1984;60:883-908 
46. Skjoth-Rasmussen J, Schulz M, Kristensen SR, Bjerre P. Delayed neurological deficit detected by an ischemic pattern in the extracellular metabolites in patients with aneurismal subarachnoid hemorrhage. J Neurosurg 2004;100:8-15

47. Smith M, Belli A, Sen J, Russo S, Petzold A, and Kitchen N. Prediction of secondary brain injury during neurocritical care: the role of cerebral microdialysis. In: Klaus, S. and Bahlmann, L., eds. Microdialysis - monitoring tissue chemistry in intensive care medicine. Lengerich: Pabst Science Publishers, 2004; 45-55.

48. Smith M. Editorial I: Neurocritical care: has it come of age? Br J Anaesth 2004;93:753-5

49. Stahl $\mathrm{N}$, Mellergard $\mathrm{P}$, Hallstrom $\mathrm{A}$, Ungerstedt $\mathrm{U}$, Nordstrom $\mathrm{CH}$. Intracerebral microdialysis and bedside biochemical analysis in patients with fatal traumatic brain lesions. Acta Anaesthesiol Scand 2001;45:977-85

50. Teasdale G.M., Graham DI. Craniocerebral trauma: protection and retrieval of the neuronal population after injury. Neurosurgery 1998;43:723-38

51. Ungerstedt, U. Measurement of neurotransmitter release by intracranial microdialysis. In: Marsden CA, eds. Measurement of Neurotransmitter Release In Vivo. Chichester: Wiley, 1984; 81-105.

52. Ungerstedt U, Pycock C. Functional correlates of dopamine neurotransmission. Bull Schweiz Akad Med Wiss 1974;30:44-55

53. Unterberg AW, Sakowitz OW, Sarrafzadeh AS, Benndorf G, Lanksch WR. Role of bedside microdialysis in the diagnosis of cerebral vasospasm following aneurysmal subarachnoid hemorrhage. J Neurosurg 2001;94:740-749

54. Valadka AB, Goodman JC, Gopinath SP, Uzura M, Robertson CS. Comparison of brain tissue oxygen tension to microdialysis-based measures of cerebral ischemia in fatally head-injured humans. J Neurotrauma 1998;15:509-19 
55. Vespa P, Martin NA, Nenov V et al. Delayed increase in extracellular glycerol with posttraumatic electrographic epileptic activity: support for the theory that seizures induce secondary injury. Acta Neurochir Supp/ 2002;81:355-7

56. Vespa PM, Boonyaputthikul R, McArthur DL et al. Intensive insulin therapy reduces microdialysis glucose values without altering glucose utilization or improving the lactate/pyruvate ratio after traumatic brain injury. Crit Care Med 2006;34:850-6

57. Vespa PM, McArthur D, O'Phelan K et al. Persistently low extracellular glucose correlates with poor outcome 6 months after human traumatic brain injury despite a lack of increased lactate: a microdialysis study. J Cereb Blood Flow Metab 2003;23:865-77

58. Vespa $\mathrm{P}$, Bergsneider $\mathrm{M}$, Hattori $\mathrm{N}$ et al. Metabolic crisis without brain ischemia is common after traumatic brain injury: a combined microdialysis and positron emission tomography study. J Cereb Blood Flow Metab 2005;25:763-74

59. Zauner A, Doppenberg E, Woodward J, Choi S, Young H, Bullock R. Continuous monitoring of cerebral substrate delivery and clearance: initial experience in 24 patients with severe acute brain injuries. Neurosurgery 1997;41:1082-93 


\section{Table 1}

Suggested normal concentrations of commonly measured biochemical markers in microdialysate samples from the uninjured human brain, collected at a perfusate flow rate of

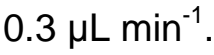

\begin{tabular}{lcc}
\hline Microdialysate concentration & $\begin{array}{c}\text { Normal value } \pm \text { SD } \\
\text { Reinstrup et al. }{ }^{37}\end{array}$ & $\begin{array}{c}\text { Normal value } \pm \text { SD } \\
\text { Schulz et al. }{ }^{43}\end{array}$ \\
\hline Glucose $\left(\mathrm{mmol} \mathrm{I}^{-1}\right)$ & $1.7 \pm 0.9$ & $2.1 \pm 0.2$ \\
Lactate $\left(\mathrm{mmol} \mathrm{I}^{-1}\right)$ & $2.9 \pm 0.9$ & $3.1 \pm 0.3$ \\
Pyruvate $\left(\mu \mathrm{mol} \mathrm{I}^{-1}\right)$ & $166 \pm 47$ & $151 \pm 12$ \\
Lactate:pyruvate ratio & $23 \pm 4$ & $19 \pm 2$ \\
Glycerol $\left(\mu \mathrm{mol} \mathrm{I}^{-1}\right)$ & $82 \pm 44$ & $82 \pm 12$ \\
Glutamate $\left(\mu \mathrm{mol} \mathrm{l}^{-1}\right)$ & $16 \pm 16$ & $14.0 \pm 3.3$ \\
\hline
\end{tabular}




\section{Table 2}

Biochemical markers of secondary brain injury.

\begin{tabular}{|c|c|c|}
\hline $\begin{array}{l}\text { Microdialysis } \\
\text { variable }\end{array}$ & Secondary injury process & Comments \\
\hline Low Glucose & $\begin{array}{l}\text { - Hypoxia/ischaemia } \\
\text { - Reduced cerebral glucose supply } \\
\text { - } \text { Cerebral hyperglycolysis }\end{array}$ & $\begin{array}{l}\text { - Should be interpreted in } \\
\text { association with serum } \\
\text { glucose concentration }\end{array}$ \\
\hline $\begin{array}{l}\text { Increased } \\
\text { lactate:pyruvate } \\
\text { ratio }\end{array}$ & $\begin{array}{ll}\text { - } & \text { Hypoxia/ischaemia } \\
\text { - } & \text { Reduction in cellular redox state } \\
\text { - } & \text { Reduced cerebral glucose supply } \\
\text { - } & \text { Mitochondrial dy\{Vespa, } 2003146 \\
& \text { /id\}sfunction }\end{array}$ & $\begin{array}{l}\text { - Most reliable biomarker } \\
\text { of ischaemia } \\
\text { - Independent of catheter } \\
\text { recovery } \\
\text { - Tissue hypoxic threshold } \\
\text { for raised LPR not } \\
\text { established }\end{array}$ \\
\hline Increased glycerol & $\begin{array}{l}\text { - Hypoxia/ischaemia } \\
\text { - Cell membrane degradation }\end{array}$ & $\begin{array}{l}\text { Increased glycerol may } \\
\text { also occur due to spill } \\
\text { over from systemic } \\
\text { glycerol or from the } \\
\text { formation of glycerol from } \\
\text { glucose }\end{array}$ \\
\hline $\begin{array}{l}\text { Increased } \\
\text { glutamate }\end{array}$ & $\begin{array}{l}\text { - Hypoxia/ischaemia } \\
\text { - Excitotoxicty }\end{array}$ & $\begin{array}{l}\text { - Wide variability in } \\
\text { glutamate levels within } \\
\text { and between patients }\end{array}$ \\
\hline
\end{tabular}




\section{LEGENDS TO FIGURE}

\section{Figure 1}

Components of clinical microdialysis catheter.

1. pump connector

2. inlet tube

3. microdialysis catheter

4. microdialysis membrane

5. outlet tube

6. microvial holder

7. microvial for collection of microdialysate

\section{Figure 2}

Schematic representation of microdialysis catheter in brain tissue. Fluid isotonic to the brain extracellular fluid is pumped through the microdialysis catheter at a rate of $0.3 \mu \mathrm{L} \mathrm{min}^{-1}$. Molecules at high concentration in the brain extracellular fluid equilibrate across the semipermeable microdialysis membrane and can be analysed in the collected perfusate (the microdialysate).

\section{Figure 3}

Schematic representation of relationship between blood capillary and microdialysis catheter in brain tissue. The microdialysis catheter acts an artificial blood capillary and the concentration of substrate in the collected fluid (microdialysate) is related to the balance between substrate delivery to, and uptake/excretion from, the extracellular fluid. 


\section{Figure 4}

Changes in lactate:pyruvate ratio in 'at risk' $(A)$ and normal $(B)$ brain during a period of low and normal cerebral perfusion pressure. The normal range for lactate:pyruvate ratio is shown by the shaded area. Note the rise in lactate:pyruvate ratio in the 'at risk' tissue during a period of cerebral hypoperfusion with normal values measured by the catheter in normal brain. 